\title{
Diabetic Foot Ulcer Infections and Pseudomonas aeruginosa Biofilm Production During the COVID-19 Pandemic
}

\author{
Marwa A. Yakout* (D) and Ibrahim A. Abdelwahab \\ Department of Microbiology and immunology, Faculty of Pharmacy, Pharos University in Alexandria, Egypt.
}

\begin{abstract}
During the different waves of the coronavirus (COVID-19) pandemic, there has been an increased incidence of diabetes mellitus and diabetic foot infections. Among gram-negative bacteria, Pseudomonas aeruginosa is the predominant causative agent for diabetic foot ulcer infections in lowresource countries. $P$. aeruginosa possesses a variety of virulence factors, including biofilm formation. Biofilm formation is an important benchmark characteristic in the pathophysiology of diabetic foot ulceration. The main objective of the current study was to identify the most commonly isolated organisms and their antibiotic susceptibility patterns in diabetic foot patients during the COVID-19 pandemic. We also determined the genes associated with bacterial persistence and biofilm formation in the predominantly isolated organism. Accordingly, 100 wound swab samples were collected from diabetic foot patients from different hospitals in Alexandria, Egypt. Through phenotypic detection of biofilm formation, $93 \%(40)$ of the 43 P. aeruginosa isolates examined were categorized as biofilm producers. Molecular detection of the biofilm-encoding genes among the $43 P$. aeruginosa isolates was as follows: algD (100\%), pelF (88\%) and psID (49.7\%), and this highlights a need for biofilm formation inhibitors to prevent the persistence of bacterial pathogens, and thus achieve better clinical outcomes in diabetic foot ulcer infections.
\end{abstract}

Keyword: Diabetic foot ulcer infections, Pseudomonas aeruginosa, biofilm, COVID-19

*Correspondence: marwa.atef@pua.edu.eg; +201224296850

(Received: October 28, 2021; accepted: December 3, 2021)

Citation: Yakout MA, Abdelwahab IA. Diabetic Foot Ulcer Infections and Pseudomonas aeruginosa Biofilm Production During the COVID-19 Pandemic. J Pure Appl Microbiol. 2022;16(1):138-146. doi: 10.22207/JPAM.16.1.02

(C) The Author(s) 2022. Open Access. This article is distributed under the terms of the Creative Commons Attribution 4.0 International License which permits unrestricted use, sharing, distribution, and reproduction in any medium, provided you give appropriate credit to the original author(s) and the source, provide a link to the Creative Commons license, and indicate if changes were made. 


\section{INTRODUCTION}

According to the International Diabetes Federation, there has been an increased incidence of diabetes mellitus (DM) during the different waves of the coronavirus (COVID-19) pandemic. ${ }^{1-4}$ A study in Wuhan reported that diabetic patients constituted $2-20 \%$ of all positive cases, and accounted for $7.1 \%$ of intensive care unit admissions. ${ }^{5,6}$ Another study in New York reported that $33.8 \%$ of COVID-19 positive patients were diabetic. Accordingly, several reports have attempted to determine the reason for the correlation between COVID-19 and DM. One hypothesis is that the angiotensin-converting enzyme 2 (ACE2) receptor necessary for the entry of SARS-CoV-2 is overexpressed in diabetic patients taking antidiabetic medications. ${ }^{5,7-9}$ In addition, the use of corticosteroids in COVID-19 patients increases blood glucose levels in both diabetic and non-diabetic individuals. ${ }^{5,10}$ Additionally, diabetic patients are more vulnerable to viral and bacterial infections. ${ }^{5,11}$ The COVID-19 pandemic has posed many challenges for the diabetic community, such as lack of sufficient resources, overworked health care workers, and scarcity of proper care for diabetic patients to avoid the development of infections. ${ }^{12,13}$

Diabetic foot ulcer (DFU) is a common complication of DM, with an increasing prevalence worldwide. ${ }^{14}$ Thirty-three percent of all diabetic patients are expected to be diagnosed with DFUs at least once during their lifetime. Untreated DFUs can result in leg amputations, permanent disability, and increased mortality rates in DM patients..$^{13}$ DFUs are most commonly associated with clinical infections with different etiological agents. ${ }^{15-22}$ Microbiological studies have shown that diabetic foot ulcers generally have polymicrobial etiologies. The etiological agent may differ from one individual to another, and from country to country. Aerobic gram-positive bacteria that are frequently isolated in DFUs include Staphylococcus spp. betahemolytic Streptococcus and Enterococcus spp. Escherichia coli, Proteus mirabilis, and Klebsiella pneumoniae are among the gram-negative bacteria that are most commonly isolated in DFUs. ${ }^{23} P$. aeruginosa is the predominant causative agent for DFUs in low-resource countries. ${ }^{15-22}$ Pseudomonas spp. are generally encountered in immunocompromised patients due to their high pathogenicity and variety of virulence factors, including biofilm formation. ${ }^{24}$ Virulence factors and biofilm formation are the benchmark characteristics in the pathophysiology of DFUs. ${ }^{25}$ The formation of biofilms by bacteria is considered to be the cornerstone that provides bacteria protection against several environmental factors, mediates persistence in medical devices, facilitates immune system evasion, and contributes to the development of antimicrobial resistance. ${ }^{15,21,22}$ Antibiotic resistance is a global public health concern, especially in patients with diabetic foot infections (DFIs). Multidrug resistance results in poor clinical outcomes, financial burden, and increased morbidity and mortality in DFU patients. ${ }^{23}$

The main objective of the current study was to identify the commonly isolated organisms and their antibiotic susceptibility patterns in DFU patients during the COVID-19 pandemic. In addition to phenotypic detection of biofilms, we also determined genes encoding biofilm formation in the predominantly isolated organism.

\section{MATERIALS AND METHODS}

One hundred wound swab samples were collected from DFU patients at the Vascular Surgery and Diabetic Foot Unit of Abou Hommos Central Hospital, Alexandria Main University Hospital, Mowasat Hospital, Abou Qir Central Hospital, and Medical Research Institute, in Alexandria, Egypt, between January 2020 and January 2021. The study was approved by the Ethics Committee in Pharos University in Alexandria, and all procedures were performed according to Helsinki ethical standards. Specimens were subjected to Gram staining, and were cultured in mannitol salt agar, MacConkey agar, blood agar, and Sabouraud dextrose agar (Oxoid, Cambridge, UK). Isolates were identified using standard biochemical methods, ${ }^{26}$ and $P$. aeruginosa isolates were confirmed with MALDITOF/MS (Bruker, Billerica, MA, USA). The identified stock cultures were preserved at $-80{ }^{\circ} \mathrm{C}$ in $15 \%$ glycerol.

\section{Antimicrobial susceptibility test}

Antibiotic susceptibility tests were done by disc diffusion method on Mueller-Hinton agar plates (Oxoid) according to Clinical Laboratory Standards Institute (CLSI) 2019 guidelines. ${ }^{26}$ The antibiotic discs include: Ceftazidime (CAZ, $30 \mu \mathrm{g})$, 
Cefepime (FEP, $30 \mu \mathrm{g})$, Piperacillin-tazobactam (TZP, $100 \mu \mathrm{g} / 10 \mu \mathrm{g}$ ), Aztreonam (ATM, $30 \mu \mathrm{g}$ ), Levofloxacin (LEV, $5 \mu \mathrm{g}$ ), Amikacin (AMK, $30 \mu \mathrm{g})$, Azithromycin (AZM, $15 \mu \mathrm{g})$, Erythromycin ( $E, 15$ $\mu \mathrm{g})$, Gentamycin (CN, $10 \mu \mathrm{g})$, Tetracycline (TE, 30 $\mu \mathrm{g})$, Cefoxitin (FOX, $30 \mu \mathrm{g}$ ), Chloramphenicol (C, 30 $\mu \mathrm{g})$, Ampicillin (AMP, $10 \mu \mathrm{g}$ ), Imipenem (IPM, 10 $\mu \mathrm{g})$, Linezolid (LZD, $30 \mu \mathrm{g})$, Amoxicillin-clavulanate (AMC, $20 \mu \mathrm{g} / 10 \mu \mathrm{g}$ ), and Methicillin (MET, $5 \mu \mathrm{g}$ ). Quantification of Biofilm formation by $\boldsymbol{P}$. aeruginosa

$200 \mu \mathrm{L}$ of overnight broth subculture of the tested isolates in sterile trypticase soy broth (TSB) (Oxoid), equivalent to $1.5 \times 10^{8} \mathrm{CFU} / \mathrm{mL}$, was added to each well of a 96 -well flat-bottomed microtiter plate, in triplicates. The plates were then incubated at $35{ }^{\circ} \mathrm{C}$ for $24 \mathrm{~h}$. The next day, the medium was discarded, and the wells were washed with phosphate-buffered saline (PBS, $\mathrm{pH}$ 7.2) (Sigma-Aldrich, Milan, Italy). Biofilm fixation was performed by incubating the 96-well plates at $60{ }^{\circ} \mathrm{C}$ for $1 \mathrm{~h}$. $0.1 \%$ (w/v) Crystal violet was used for staining, and was extracted with $99.5 \%$ ethanol. ${ }^{27}$ The optical density (OD) value of each well was measured at $620 \mathrm{~nm}$ on a microtitre plate ELISA reader (STATFAX2100, Fisher Bioblock scientific, France). The isolates were characterized according to their biofilm-forming ability as strong, moderate, weak, or non-biofilm producers, as previously described by Stepanovic et al. ${ }^{28}$

Molecular detection of biofilm encoding genes in $P$. aeruginosa

DNA was extracted from the $P$. aeruginosa isolates using the boiling method. ${ }^{29}$ DNA amplification was performed using Master Mix (iNtRON biotechnology, Seongnam, South Korea). The primers30 (SBS GeneTech, Beijing, China) and the annealing temperatures used are listed in Table 1. PCR program was as follows: initial denaturation at $95{ }^{\circ} \mathrm{C}$ for $5 \mathrm{~min}$, followed by denaturation at 95 ${ }^{\circ} \mathrm{C}$ for $1 \mathrm{~min}, 30$ cycles at $58^{\circ} \mathrm{C}$ for $\operatorname{alg} \mathrm{D}$, pelF and $56{ }^{\circ} \mathrm{C}$ for $p s / D$ gene for 40 seconds, then $72{ }^{\circ} \mathrm{C}$ for 45 seconds, and a final elongation at $72{ }^{\circ} \mathrm{C}$ for 5 $\min$.

PCR products were separated on $2 \%$ agarose gel in TBE buffer, stained with $2 \mu \mathrm{g} / \mathrm{mL}$ ethidium bromide, and visualized under ultraviolet transillumination (BIORAD, Italy). ${ }^{30,31}$

\section{Statistical analysis}

Statistical analysis of the data was performed using IBM SPSS software version 20.0. (IBM Corp, Armonk, NY, USA). The chi-square test and Fisher's exact test were used. Statistical significance was set at a $p$-value of $5 \%$ or lower.

\section{RESULTS}

The present study included swabs from 100 DFU patients ( 75 male and 25 female) admitted to the Vascular Surgery and Diabetic Foot Unit of Abou Hommos Central Hospital, Alexandria Main University Hospital, Mowasat Hospital, Abou Qir Central Hospital, and Medical Research Institute, Alexandria, Egypt, between January 2020 and January 2021. The ages ranged from 44 to 76 years.

\section{Microbiological Culture Results}

The microbiological culture of the 100 DFU swabs yielded monomicrobial bacterial growth in 76 samples (76\%), polymicrobial bacterial growth (2-3 microorganisms) in 20 samples (20\%), and Candida albicans in 4 samples (4\%) (Table 2).

The microbial species isolated from the DFU specimens are listed in Table 3. The

Table 1. Primers used for detection of genes involved in Biofilm formation by Pseudomonas aeruginosa

\begin{tabular}{|c|c|c|c|}
\hline Gene & Primers & $\begin{array}{l}\text { Annealing } \\
\text { Temp. }\end{array}$ & $\begin{array}{c}\text { Band } \\
\text { Size }\end{array}$ \\
\hline \multirow[t]{2}{*}{ algD } & F-CTACATCGAGACCGTCTGCC & 58 & 593 \\
\hline & R-GCATCAACGAACCGAGCATC & & \\
\hline \multirow[t]{2}{*}{ pelF } & F-GAGGTCAGCTACATCCGTCG & 58 & 789 \\
\hline & R-TCATGCAATCTCCGTGGCTT & & \\
\hline \multirow[t]{2}{*}{ psID } & F- TGTACACCGTGCTCAACGAC & 56 & 369 \\
\hline & R- CTTCCGGCCCGATCTTCATC & & \\
\hline
\end{tabular}


Table 2. Culture results of 100 diabetic foot ulcers

\begin{tabular}{lcc}
\hline Growth pattern in culture & No. & $\%$ \\
\hline Bacterial growth & 96 & 96.0 \\
Monomicrobial & 76 & 76.0 \\
Polymicrobial microorganism $(2-3)$ & 20 & 20.0 \\
Fungal growth & & \\
Candida albicans & 4 & 4.0 \\
Total & 100 & 100.0 \\
\hline
\end{tabular}

majority of the isolates were gram-negative $(88 \%)$, and $P$. aeruginosa was the predominant gram-negative bacteria isolated (43\%), followed by K. pneumoniae (21\%), P. mirabilis (11\%), E. coli (9\%), and Serratia marcescens (4\%). The grampositive bacteria isolated were S. aureus (5\%) and Enterococcus spp. (2\%). C. albicans was the only fungal species isolated (5\%).

\section{Antibiotic Susceptibility Profile}

Antibiotic susceptibility in the fortythree $P$. aeruginosa isolates was as follows: Ampicillin (100\%), followed by Aztreonam (74\%), Amikacin (72\%), Levofloxacin, Amoxicillinclavulanate (69.7\%), Cefoxitin (46.5\%), Ceftazidime $(41 \%)$, Imipenem (32.5\%), and varied degrees of resistance to other antibiotics (Table 4).

Antibiotic susceptibility profile of the twenty-one $K$. pneumoniae isolates was as follows: Ampicillin (95\%), followed by Amoxicillin-clavulanate, Levofloxacin and Cefoxitin (76\%), Amikacin (71.4\%), Aztreonam (57.1\%), and varied degrees of resistance to other antibiotics. The eleven $P$. mirabilis isolates were resistant to Aztreonam, Cefoxitin, Cefazolin and Chloramphenicol (72\%), Ampicillin, Piperacillintazobactam and Levofloxacin (63\%), Amikacin (54\%), and varied degrees of resistance to other antibiotics. Of the nine $E$. coli isolates, $77 \%$ were resistant to levofloxacin, followed by amoxicillinclavulanate, gentamycin, amikacin and cefoxitin (66\%), and ampicillin (55\%). Four isolates of S. marcescens were resistant to ampicillin (25\%) (Table 4).

Of the five $S$. aureus isolates, $96 \%$ were resistant to tetracycline and methicillin and with varying degree of resistance to other antibiotics. Of the two Enterococcus spp. isolates, $50 \%$ were resistant to cefoxitin, as shown in Table 4.
Table 3. Frequency of microbial isolates from 100 diabetic foot ulcers

\begin{tabular}{llcc}
\hline \multirow{2}{*}{ Gram reaction } & No. & $\%$ \\
\hline \multirow{2}{*}{ Gram negative } & P. aeruginosa & 43 & 43.0 \\
& K. pneumoniae & 21 & 21.0 \\
& P. mirabilis & 11 & 11.0 \\
& E. coli & 9 & 9.0 \\
Gram positive & Serratia marcescens & 4 & 4.0 \\
& S. aureus & 5 & 5.0 \\
Fungi & Enterococcus spp. & 2 & 2.0 \\
Total & C. albicans & 5 & 5.0 \\
& & 100 & 100.0 \\
\hline
\end{tabular}

\section{Quantification of Biofilm formation by $P$. aeruginosa}

Of the forty-three $P$. aeruginosa isolates examined, twenty-three $(53.5 \%)$ were strong biofilm producers, ten (23.2\%) were moderate biofilm producers, seven (16.3\%) were weak biofilm producers, and just three isolates (7\%) were non-biofilm producers.

\section{Molecular detection of Biofilm encoding genes in $P$. aeruginosa}

The following genes encoding biofilm exopolysaccharides were identified in the $43 P$. aeruginosa isolates: algD (100\%), pelF (88\%) and $p s I D(49.7 \%)$. The presence of $a \lg D, p s I D$, and pelF genes was noted in a large proportion of the 43 $P$. aeruginosa isolates. Our findings revealed that $82.6 \%$ of the 23 strong biofilm producers had the genotypic pattern alg $D+/ p s / D+/ p e l F+$, while the rest were $a \lg D-/ p s / D-/ p e l F-$. On the other hand, $66.6 \%$ of the three non-biofilm producers carried the biofilm encoding genes, as shown in Table 5.

\section{DISCUSSION}

DFU is a debilitating consequence of DM with an increasing prevalence worldwide. ${ }^{14}$ During the different waves of the COVID-19 pandemic, DM was increasingly diagnosed worldwide. Based on the recommendation of the International Diabetes Federation, increased care should be given to diabetic patients to avoid the devastating complications of DM. ${ }^{1-4}$ Among the hypothesized reasons contributing to the increased incidence of DFIs during the COVID-19 pandemic is the increased expression of the ACE2 receptor necessary for the entry of SARS-CoV-2 
in diabetic patients. ${ }^{5,7-9}$ Other reported reasons include the rise in blood glucose levels noted in patients receiving corticosteroids. ${ }^{5,10}$ Additionally, diabetic patients are more vulnerable to viral and bacterial infections. ${ }^{5,11}$ Other challenges contributing to the increased incidence of DFIs include a lack of sufficient resources, overworked health care workers, and a scarcity of proper care for diabetic patients to avoid the development of infections. ${ }^{13}$

The present study included swab samples from 100 patients with DFUs (75 male and 25 female). Other studies have also supported the male predominance of foot ulceration and its associated complications. ${ }^{32,33}$ Culture results of the 100 specimens showed $76 \%$ monomicrobial bacterial growth, $20 \%$ polymicrobial bacterial growth, and $4 \%$ fungal growth. Hitam et al. also reported a similar percentage (28.8\%) of polymicrobial infections in DFI patients. ${ }^{34}$ Additionally, culture results showed that the majority of isolates were gram-negative (88\%) bacteria, and $P$. aeruginosa was the predominant microorganism isolated (43\%), followed by $K$. pneumoniae (21\%), P. mirabilis (11\%), E. coli (9\%), and S. marcescens (4\%). Among grampositive bacteria, $S$. aureus was the most common isolate. Pseudomonas spp. was regarded as the main causative agent of DFI by Hitam et al., ${ }^{34}$ Hatipoglu et al., ${ }^{35}$ Hobizal et al., ${ }^{36}$ and Ramakant et al. ${ }^{37} P$. aeruginosa is also reported to be the most predominant causative agent for DFIs in low-resource countries. ${ }^{15-22} P$. aeruginosa should not be regarded as a normal flora in burn wounds and diabetic foot patients. P. aeruginosa can cause extensive tissue damage in diabetic patients and result in sepsis. ${ }^{24}$ Additionally, S. aureus has been reported to be the most common gram-positive etiological pathogen of DFI. ${ }^{34-37}$

Antibiotic susceptibility testing revealed that $100 \%$ of the forty-three $P$. aeruginosa isolates were resistant to Ampicillin, followed by Aztreonam (74\%), Amikacin (72\%), Levofloxacin, Gentamycin and Amoxicillin-clavulanate (69.7\%), Cefoxitin (46.5\%), Ceftazidime (41\%), Imipenem $(32.5 \%)$, and varied degrees of resistance to other antibiotics was observed. Multidrug resistance (MDR) was observed in 30 (69.7\%) of the $P$. aeruginosa isolates. Sivanmaliappan et al. ${ }^{24}$ reported that $55.5 \%$ of $P$. aeruginosa were 
Table 5. Relationship between phenotypic biofilm characteristic and genotypic biofilm characteristic among $P$. aeruginosa isolates (Manual)

\begin{tabular}{lcccc}
\hline $\begin{array}{l}\text { Phenotypic pattern } \\
\text { of biofilm, no. (\%) }\end{array}$ & \multicolumn{2}{c}{ Genotypic pattern of biofilm, no. (\%) } & \multirow{2}{*}{$\chi^{2}$} & \multirow{2}{*}{ FEp } \\
\cline { 2 - 4 } AlgD +/psID +/pelf + & AlgD -/pslD -/pelf - & & \\
\hline Strong 23 (53.5\%) & $19(82.6 \%)$ & $4(17.4 \%)$ & 0.953 & 0.473 \\
Moderate $10(23.2 \%)$ & $7(70 \%)$ & $3(30 \%)$ & 0.332 & 0.674 \\
Weak 7 (16.3\%) & $5(71.4 \%)$ & $2(28.6 \%)$ & 0.132 & 0.656 \\
Non 3 (7\%) & $2(66.6 \%)$ & $1(33.4 \%)$ & 0.184 & 0.558 \\
Total & 33 & 10 & & \\
\hline
\end{tabular}

$\chi^{2}$ : Chi-square test, FE: Fisher Exact, p: p-value for comparing between the studied groups

multidrug resistant (MDR); $100 \%$ were resistant to ampicillin, $83.3 \%$ to piperacillin, and $66.6 \%$ to ceftazidime, gentamycin and imipenem. However, our results show that ceftazidime, imipenem, and piperacillin/tazobactam combination display higher activity as antipseudomonal agents. Banar et al. ${ }^{30}$ also stated that ceftazidime displayed high activity in $P$. aeruginosa isolates. In a study on DFI in Tanzania, resistance was noted for all commonly used antibiotics, except imipenem (100\% sensitivity). This can be attributed to the fact that imipenem is expensive in low-resource countries. ${ }^{38}$ Previous reports described the increased efficacy of piperacillin-tazobactam against several virulence traits, such as adhesion, biofilm production, and flagellin production. ${ }^{39}$ The increased prevalence of MDR has been noted in different studies worldwide..$^{30,31,40,41}$ This can be attributed to extensive use of antibiotics, which gives a selective advantage for survival of pathogenic bacterial strains. MDR $P$. aeruginosa guarded by biofilms that are difficult to penetrate can survive and develop more resistance. ${ }^{41,42}$

Biofilm production is the benchmark characteristic for the development of DFIs, and provides a balance between colonization and infection. ${ }^{25}$ Bacteria within biofilms produce their own matrix of extracellular polymeric substances (EPS). EPS contains glycoproteins and polysaccharides that provide protection against several environmental factors, mediate persistence in medical devices, facilitate immune system evasion, and contribute to the development of antimicrobial resistance. ${ }^{15,21,22}$ There are three major exopolysaccharides that significantly contribute to the formation and stabilization of the biofilm matrix of $P$. aeruginosa. The pentasaccharide $P s /$ is essential to promote both cell-cell and cell-surface interactions, thereby initiating biofilm formation and providing structural support to the formed biofilm. The PsID protein is encoded by the $p s / D$ gene, a part of the $p s /$ operon. The PsID protein is located in the periplasm/outer membrane and contributes to the export of essential biofilm exopolysaccharides. Alginate is another important polymer that significantly stabilizes biofilm formation and provides additional protection. The synthesis of alginate protein is mediated by the algACD operon. The $\operatorname{alg} D$ gene controls the synthesis of the alginate proteins. The $\operatorname{alg} D$ gene controls the production of the final precursor, GDP-mannuronic acid, one of the two monomers of alginate. The pellicle operon controls the synthesis of the third major exopolysaccharide, the Pel protein, which is responsible for pellicle formation. ${ }^{30,31}$

In this context, biofilm formation was evaluated both phenotypically using the crystal violet assay, in addition to molecular detection of genes responsible for biofilm formation, $\operatorname{alg} D$, $p s / D$, and pelf. Phenotypic characterization revealed that $93 \%(40)$ of the $43 P$. aeruginosa isolates examined were biofilm producers; $53.4 \%$ (23) of $P$. aeruginosa isolates were strong biofilm producers, $23.3 \%$ (10) were moderate biofilm producers, $16.3 \%$ (7) were weak biofilm producers, and only $6.9 \%$ (3) were non-biofilm producers. Kamali et al. reported that $83.75 \%$ of their $P$. aeruginosa isolates were biofilm producers with variable degrees of biofilm production. ${ }^{31}$ Banar et al. ${ }^{30}$ reported that out of $57 P$. aeruginosa isolates tested $55(96.5 \%)$ isolates were biofilm producers 
with variable degrees of biofilm production, and only 2 (3.5\%) isolates were regarded as non-biofilm producers.

The frequency of genes encoding biofilm exopolysaccharides among the $43 P$. aeruginosa isolates was as follows: algD (100\%), pelF (88\%) and $p s / D(49.7 \%)$. The present study showed a high prevalence of all three genes, $\operatorname{alg} D, p s / D$, and pelf, in a considerable proportion of the $P$. aeruginosa isolates. Approximately $82.6 \%$ of the 23 strong biofilm producers showed a algD +/ps/D +/pelF + genotypic pattern, while $17.4 \%$ showed algD -/ psID -/pelF -.

Banar et al. ${ }^{30}$ also reported similar frequencies of biofilm genes: pelF (93\%), ps/D (54.65\%), and $\operatorname{alg} D(100 \%)$, with $\operatorname{alg} D+/ p s / D+/$ pelF + being the predominant genotypic pattern among their isolates. Another study by Kamali et al.31 reported that $a \lg D+/ p s / D+/ p e l F+$ genotypic pattern $(87.5 \%)$ was the predominant pattern among their isolates. Pournajaf et al. ${ }^{43}$ reported that the frequency of $p s I D$ and pelF genes was $89.5 \%$ and $57.3 \%$, respectively, in their isolates. Ghadaksaz et al. ${ }^{44}$ reported a frequency of $83.7 \%$ for $p s / D$ and $45.2 \%$ for pelF in their isolates. However, to the best of our knowledge, only a few studies have investigated the presence of biofilmencoding genes, $a / g D, p s / D$, and pelf. ${ }^{31}$

\section{CONCLUSION}

During the different waves of the COVID-19 pandemic, there has been an increased incidence of DM and DFIs. $P$. aeruginosa is the predominant etiological agent for DFIs. In the present study, the majority of $P$. aeruginosa isolates were MDR and biofilm producers. A high prevalence of biofilm-encoding genes were identified in this study, highlighting a need for inhibitors of biofilm formation to prevents the persistence of bacterial pathogens, and thereby achieve better clinical outcomes.

\section{ACKNOWLEDGMENTS}

The authors thank Pharos University in Alexandria and Medical technology centre for their technical support.

\section{CONFLICT OF INTEREST}

The authors declare that there is no conflict of interest.

\section{AUTHORS' CONTRIBUTION}

Both the authors listed have made a substantial, direct and intellectual contribution to the work, and approved it for publication.

\section{FUNDING}

None.

\section{DATA AVAILABILTY}

All datasets generated or analyzed during this study are included in the manuscript.

\section{ETHICS STATEMENT}

The study was approved by the Unit of Research Ethics Approval Committee [UREAC], Pharos University in Alexandria, Egypt.

\section{REFERENCES}

1. Rastogi A, Hiteshi P, Bhansali AA, Jude EB. Virtual triage and outcomes of diabetic foot complications during COVID-19 pandemic: A retroprospective, observational cohort study. PLOS One. 2021;16(5):e0251143. doi: 10.1371/journal. pone. 0251143

2. Chaudhary S, Bhansali A, Rastogi A. Mortality in Asian Indians with Charcot's neuroarthropathy: a nested cohort prospective study. Acta Diabetol. 2019;56(12):1259-1264. doi: 10.1007/s00592-01901376-9

3. Rastogi A, Goyal G, Kesavan R, et al. Long term outcomes after incident diabetic foot ulcer: Multicenter large cohort prospective study (EDI-FOCUS investigators) epidemiology of diabetic foot complications study. Diabetes Res Clin Pract. 2020;162:108113. doi: 10.1016/j.diabres.2020.108113

4. American Diabetes Association (ADA). 11. Microvascular Complications and Foot Care: Standards of Medical Care in Diabetes-2020. Diabetes Care. 2020;43(Suppl 1):S135-s151. doi: 10.2337/dc20-S011

5. Ugwueze CV, Ezeokpo BC, Nnolim BI, Agim EA, Anikpo NC, Onyekachi KE. COVID-19 and Diabetes Mellitus: The Link and Clinical Implications. Dubai Diabetes Endocrinol J. 2020;26(2):69-77. doi: 10.1159/000511354

6. Huang C, Wang Y, Li X, et al. Clinical features of patients infected with 2019 novel coronavirus in Wuhan, China. Lancet. 2020;395(10223):497-506. doi: 10.1016/ S0140-6736(20)30183-5

7. Li XC, Zhang J, Zhuo JL. The vasoprotective axes of the renin-angiotensin system: Physiological relevance and therapeutic implications in cardiovascular, hypertensive and kidney diseases. Pharmacol Res. 2017;125(Pt A):21-38. doi: 10.1016/j.phrs.2017.06.005

8. European Societies of Cardiology Position statement of ESC Council on Hypertension on ACE-inhibitors and angiotensin receptor blockers. March 13, 2020 [Online] Available from: https//:www.escardio.org/Councils/ 
Council-on-hypertension-(CHT)/News/Position statement-of the esc-council-on hypertension-on-ace inhibitors and angiotensin receptor blockers. Accessed 2020 May 16.

9. Liu C, Li Y, Guan T, et al. ACE2 polymorphisms associated with cardiovascular risk in Uygurs with type 2 diabetes mellitus. Cardiovasc Diabetol. 2018;17(1):127. doi: 10.1186/s12933-018-0771-3

10. Yang JK, Feng Y, Yuan MY, et al. Plasma glucose levels and diabetes are independent predictors for mortality and morbidity in patients with SARS. Diabet Med. 2006;23(6):623-628. doi: 10.1111/j.14645491.2006.01861.x

11. Muniyappa R, Gubbi S. COVID-19 pandemic, coronaviruses, and diabetes mellitus. Am J Physiol Endocrinol Metab. 2020;318(5):E736-e741. doi: 10.1152/ajpendo.00124.2020

12. Riddle MC, Buse JB, Franks PW, et al. COVID-19 in People With Diabetes: Urgently Needed Lessons From Early Reports. Diabetes Care. 2020;43(7):1378-1381. doi: $10.2337 /$ dci20-0024

13. Boulton AJM. Diabetic Foot Disease during the COVID-19 Pandemic. Medicina (Kaunas). 2021;57(2):97. doi: 10.3390/medicina57020097

14. Adeleye OO, Ugwu ET, Gezawa ID, Okpe I, Ezeani I, Enamino M. Predictors of intra-hospital mortality in patients with diabetic foot ulcers in Nigeria: data from the MEDFUN study. BMC Endocr Disord. 2020;20(1):134. doi: 10.1186/s12902-020-00614-4

15. Mutonga DM, Mureithi MW, Ngugi NN, Otieno FCF. Bacterial isolation and antibiotic susceptibility from diabetic foot ulcers in Kenya using microbiological tests and comparison with RT-PCR in detection of $S$. aureus and MRSA. BMC Res Notes. 2019;12(1):244. doi: 10.1186/s13104-019-4278-0

16. Mendes J, Neves J. Diabetic foot infections: current diagnosis and treatment. J Diabet Foot Complicat. 2012:4(2):26-45.

17. Uckay I, Gariani K, Pataky Z, Lipsky BA. Diabetic foot infections: state-of-the-art. Diabetes Obes Metab. 2014;16(4):305-316. doi: 10.1111/dom.12190

18. Lipsky BA, Richard JL, Lavigne JP. Diabetic foot ulcer microbiome: one small step for molecular microbiology. One giant leap for understanding diabetic foot ulcers? Diabetes. 2013;62(3):679-681. doi: 10.2337/db12-1325

19. Stappers MHT, Hagen F, Reimnitz P, Mouton JW, Meis JF, gyssens IC. Direct molecular versus culturebased assessment of Gram-positive cocci in biopsies of patients with major abscesses and diabetic foot infections. Eur J Clin Microbiol Infect Dis. 2015;34(9):1885-1892. doi: 10.1007/s10096-0152428-4

20. Messad N, Prajsnar TK, Lina G, et al. Existence of a Colonizing Staphylococcus aureus Strain Isolated in Diabetic Foot Ulcers. Diabetes. 2015;64(8):2991-2995. doi: 10.2337/db15-0031

21. Spichler A, Hurwitz BL, Armstrong DG, Lipsky BA. Microbiology of diabetic foot infections: from Louis Pasteur to 'crime scene investigation'. BMC Med. 2015;13(1):2. doi: 10.1186/s12916-014-0232-0

22. Banu A, Noorul Hassan MM, Rajkumar J, Srinivasa S.
Spectrum of bacteria associated with diabetic foot ulcer and biofilm formation: A prospective study. Australas Med J. 2015;8(9):280-285. doi: 10.4066/ AMJ.2015.2422

23. Shahi SK, Kumar A. Isolation and Genetic Analysis of Multidrug Resistant Bacteria from Diabetic Foot Ulcers. Front Microbiol. 2015;6:1464. doi: 10.3389/ fmicb.2015.01464

24. Sivanmaliappan TS, Sevanan M. Antimicrobial Susceptibility Patterns of Pseudomonas aeruginosa from Diabetes Patients with Foot Ulcers. Int J Microbiol. 2011;2011:605195. doi: 10.1155/2011/605195

25. Pouget $C$, Dunyach-Remy C, Pantel A, Schuldiner S, Sotto A, Lavigne J-P. Biofilms in Diabetic Foot Ulcers: Significance and Clinical Relevance. Microorganisms. 2020;8(10):1580. doi: 10.3390/ microorganisms 8101580

26. Clinical and laboratory standards institute (CLSI). Performance standards for antimicrobial susceptibility testing: CLSI Supplement M100. $29^{\text {th }}$ Ed. CLSI, Wayne, PA, 2019.

27. Alcaraz E, Garcia C, Papalia M, Vay C, Friedman L, de Rossi BP. Stenotrophomonas maltophilia isolated from patients exposed to invasive devices in a university hospital in Argentina: molecular typing, susceptibility and detection of potential virulence factors. J Med Microbiol. 2018;67(7):992-1002. doi: 10.1099/ jmm.0.000764

28. Stepanovic S, Vukovic D, Hola V, et al. Quantification of biofilm in microtiter plates: overview of testing conditions and practical recommendations for assessment of biofilm production by staphylococci. Apmis. 2007;115(8):891-899. doi: 10.1111/j.16000463.2007.apm_630.x

29. Sambrook J, Russell D. Molecular Cloning: Laboratory Manual. Cold Spring Harbor Laboratory Press, New York. 2001.

30. Banar M, Emaneini M, Satarzadeh M, et al. Evaluation of Mannosidase and Trypsin Enzymes Effects on Biofilm Production of Pseudomonas aeruginosa Isolated from Burn Wound Infections. PLoS One. 2016;11(10):e0164622. doi: 10.1371/journal. pone. 0164622

31. Kamali E, Jamali A, Ardebili A, Ezadi F, Mohebbi A. Evaluation of antimicrobial resistance, biofilm forming potential, and the presence of biofilm-related genes among clinical isolates of Pseudomonas aeruginosa. BMC Res Notes. 2020;13(1):27. doi: 10.1186/s13104020-4890-z

32. Jarl G, Alnemo J, Tranberg R, Lundqvist L-O. Gender differences in attitudes and attributes of people using therapeutic shoes for diabetic foot complications. J Foot Ankle Res. 2019;12:21. doi: 10.1186/s13047-0190327-0

33. Dinh T, Veves A. The influence of gender as a risk factor in diabetic foot ulceration. Wounds. 2008;20(5):127131.

34. Hitam SAS, Hassan SA, Maning N. The Significant Association between Polymicrobial Diabetic Foot Infection and Its Severity and Outcomes. Malays J Med Sci. 2019;26(1):107-114. doi: 10.21315/ mjms2019.26.1.10 
35. Hatipoglu M, Mutluoglu M, Uzun G, Karabacak E, Turhan V, Lipsky BA. The microbiologic profile of diabetic foot infections in Turkey: a 20 -year systematic review: diabetic foot infections in Turkey. Eur J Clin Microbiol Infect Dis. 2014;33(6):871-878. doi: 10.1007/ s10096-014-2047-5

36. Hobizal KB, Wukich DK. Diabetic foot infections: current concept review. Diabet Foot Ankle. 2012;3:18409. doi: 10.3402/dfa.v3i0.18409

37. Ramakant P, Verma AK, Misra R, et al. Changing microbiological profile of pathogenic bacteria in diabetic foot infections: time for a rethink on which empirical therapy to choose? Diabetologia. 2011;54(1):58-64. doi: 10.1007/s00125-010-1893-7

38. Chalya PL, Mabula JB, Dass RM, et al. Surgical management of Diabetic foot ulcers: A Tanzanian university teaching hospital experience. $B M C$ Res Notes. 2011;4:365. doi: 10.1186/1756-0500-4-365

39. Zhang J, Chu Y, Wang P, et al. Clinical outcomes of multidrug resistant pseudomonas aeruginosa infection and the relationship with type III secretion system in patients with diabetic foot. Int J Low Extrem Wounds. 2014;13(3):205-210. doi: 10.1177/1534734614545878

40. Srivastava P, Sivashanmugam K. Combinatorial Drug Therapy for Controlling Pseudomonas aeruginosa and
Its Association With Chronic Condition of Diabetic Foot Ulcer. Int J Low Extrem Wounds. 2020;19(1):7-20. doi: 10.1177/1534734619873785

41. Zubair M, Malik A, Ahmad J. Clinico-microbiological study and antimicrobial drug resistance profile of diabetic foot infections in North India. Foot (Edinb). 2011;21(1):6-14. doi: 10.1016/j.foot.2010.10.003

42. Matta-Gutiérrez G, García-Morales E, García-Álvarez Y, Álvaro-Afonso FJ, Molines-Barroso RJ, Lázaro-Martínez $\mathrm{JL}$. The Influence of Multidrug-Resistant Bacteria on Clinical Outcomes of Diabetic Foot Ulcers: A Systematic Review. J Clin Med. 2021;10(9):1948. doi: 10.3390/ jcm10091948

43. Pournajaf A, Razavi S, Irajian G, et al. Integron types, antimicrobial resistance genes, virulence gene profile, alginate production and biofilm formation in Iranian cystic fibrosis Pseudomonas aeruginosa isolates. Infez Med. 2018;26(3):226-236. PMID: 30246765

44. Ghadaksaz A, Fooladi IAA, Mahmoodzadeh Hosseini $\mathrm{H}$, Amin M. The prevalence of some Pseudomonas virulence genes related to biofilm formation and alginate production among clinical isolates. J Appl Biomed. 2015;13(1):61-68. doi: 10.1016/j. jab.2014.05.002 